\title{
Management of Huntington's disease: role of tetrabenazine
}

\author{
This article was published in the following Dove Press journal: \\ Therapeutics and Clinical Risk Management \\ I8 March 201। \\ Number of times this article has been viewed
}

\section{Marina de Tommaso \\ Claudia Serpino \\ Vittorio Sciruicchio}

Neurological and Psychiatric Sciences Department, University of Bari Aldo

Moro, Bari, Italy
Correspondence: Marina de Tommaso Neurological and Psychiatric Sciences Department, University of Bari Aldo Moro, Neurological Building, Policlinico General Hospital, Piazza Giulio

Cesare II, 70124 Bari, Italy

$\mathrm{Tel}+390805478565$

$\mathrm{Fax}+390805478532$

Email m.detommaso@neurol.uniba.it
Abstract: Huntington's disease (HD) is an autosomal dominant neurodegenerative disorder characterized by progressive involuntary movements, neuropsychiatric disturbances, and cognitive impairment. The use of tetrabenazine (TBZ), a specific inhibitor of vesicular monoamine transporter, is approved for chorea in HD patients. We aimed to review the medical literature concerning the efficacy and tolerability of TBZ in the treatment of HD patients and to report our personal experience about TBZ use in a cohort of HD patients. We searched PubMed (1960 to July 2010) using the following keywords: "tetrabenazine" + "huntington's disease + chorea". We included randomized controlled trials, open-label trials, and retrospective studies. We excluded case reports and studies conducted on fewer than 20 patients. In addition, we retrospectively evaluated 2 years' follow-up of TBZ treatment on motor and cognitive performances and functional abilities in $28 \mathrm{HD}$ patients, compared with 10 patients treated by other neuroleptics (clotiapine). Only four papers fulfilled the requested criteria. In the first study, which included 84 randomized outpatients, TBZ showed a significant improvement of chorea compared with placebo. In the open-label study extension, TBZ confirmed its efficacy on chorea, with a frequent occurrence of withdrawals due to side effects. In a retrospective study of long-term efficacy, 63 patients under TBZ therapy for an average period of 34 months showed a stable effect on chorea, despite a slight reduction of effect over time. In a telephone survey conducted on a total of 118 patients affected by different movement disorders, TBZ showed the most favorable effect for the 28 included HD patients. Our HD patients showed a slight deterioration of motor performances over time that was nonsignificant compared with TBZ or clotiapine treatments. Despite the fact that the global effect of TBZ seems positive in HD, more attention on evaluating symptomatic treatments for cognitive and psychiatric deterioration as well as motor deterioration would alleviate this devastating disorder until a neuroprotective treatment becomes available.

Keywords: Huntington's disease, symptomatic treatment, tetrabenazine

\section{Introduction}

Huntington's disease (HD) is an autosomal dominant neurodegenerative disorder characterized by midlife onset and a triad of symptoms, including progressive involuntary movements, neuropsychiatric disturbances, and cognitive impairment. ${ }^{1}$ $\mathrm{HD}$ is caused by an enlarged CAG repeat expansion in the huntingtin protein gene on the short arm of chromosome 4 , which results in a diffuse neuronal degeneration preferentially involving striatum and cortex. ${ }^{2}$ As the disease progresses, motor disability develops, especially stereotypic involuntary movements (Huntington's chorea). There is no provided treatment for delaying the development of the disease or to stop the progression of HD. The current management of HD is focused on symptom reduction, 
because there is no treatment able to avoid the progressive global deterioration and death occurring within 10-20 years of disease onset. The goals of managing HD are to reduce the impact of the disease on individuals' abilities, primarily improving motor function, in order to obtain a favorable impact on their quality of life.

Movement disorders in HD consist of involuntary movements (chorea and dystonia) and impairment of voluntary movements (eg, gait, speech, swallowing, fine motor tasks). Both chorea and impairment of voluntary movements progress in the middle stages of HD, whereas in the progression of the disease, chorea often decline as patients become rigid and unable to initiate voluntary movements. Some medications that are effective on chorea may worsen voluntary movement, compromising gait or swallowing, and may induce depression, sedation, and tardive dyskinesia. Many pharmacological interventions have been reported in HD for their efficacy in the treatment of movement disorders such as hyperkinesias, dystonia, myoclonus, and tics. Among them, neuroleptics have demonstrated effectiveness in the treatment of chorea but may induce side effects on motor performance. ${ }^{3,4}$

Tetrabenazine (TBZ; Ro 1-9569) was first synthesized in 1956, and in 1958 was approved for the treatment of neuroses and psychoses/schizophrenia in Finland, the Netherlands,
Switzerland, and the UK. Since the 1980s, TBZ has been used in the treatment of different dyskinesias. In May 2008, it was approved by the US Food and Drug Administration for the treatment of chorea in HD. To date, TBZ is marketed with the same indication in many other countries. ${ }^{5} \mathrm{TBZ}$ exerts its antichoreic effects by reducing the amount of dopamine in the brain in two ways. ${ }^{6}$ The first and more widely recognized way is by preventing dopamine release from vesicles, inhibiting the uptake of monoamines. Special proteins called vesicular monoamine transporters (VMATs) are responsible for neurotransmitter transport into the vesicles. TBZ binds to the VMATs, preventing them from performing this function. As such, neurotransmitters like dopamine are not stored in vesicles and cannot be released into the synapse. The highest binding density for TBZ is in the caudate nucleus, putamen, and nucleus accumbens, areas known to bear the brunt of pathology in HD. ${ }^{7,8}$

In addition, TBZ reduces dopamine by blocking dopamine receptors, as has been shown in in vitro studies. ${ }^{9,10}$ TBZ binds to receptors on the surface of the receiving nerve cell, blocking dopamine from passing on its message. The mechanism of inhibiting dopamine receptors, however, is thought to be less significant at the TBZ dosages used in HD patients, although it may possibly be responsible for acute dystonic reactions, which are rarely reported with TBZ. ${ }^{11}$

Table I Main data across the selected studies about TBZ in HD patients

\begin{tabular}{|c|c|c|c|c|c|c|}
\hline Study & Year & Study design & $\begin{array}{l}\text { No. of HD patients } \\
\text { under TBZ }\end{array}$ & $\begin{array}{l}\text { No. of HD } \\
\text { patients on } \\
\text { placebo }\end{array}$ & $\begin{array}{l}\text { No. of } \\
\text { follow-up }\end{array}$ & $\begin{array}{l}\text { Maximum time } \\
\text { of observation }\end{array}$ \\
\hline Paleacu et al ${ }^{18}$ & 2004 & $\begin{array}{l}\text { Open-label long-term } \\
\text { follow-up }\end{array}$ & $\begin{array}{l}28 \text { (HD plus other types } \\
\text { of chorea) among a total of } \\
\text { I50 patients with different } \\
\text { movement disorders }\end{array}$ & & & 88 weeks \\
\hline $\begin{array}{l}\text { Huntington } \\
\text { Study Group }\end{array}$ & 2006 & $\begin{array}{l}\text { Multicenter, prospective, } \\
\text { double-blind, } \\
\text { placebo-controlled, } \\
\text { dose-finding }\end{array}$ & 54 & 30 & I & 12 weeks \\
\hline Fasano et $\mathrm{al}^{17}$ & 2008 & $\begin{array}{l}\text { Long-term } \\
\text { retrospective }\end{array}$ & 68 & 0 & 2 & $137.6+100$ weeks \\
\hline
\end{tabular}


Our aim was to review the medical literature concerning the efficacy and tolerability of TBZ in the treatment of chorea in HD patients. In addition, we aimed to report our personal experience about TBZ use in a cohort of HD patients.

\section{Materials and methods}

We searched PubMed (1960 to July 2010) using the following keywords: "tetrabenazine" + "huntington's disease + chorea". We included randomized controlled trials, openlabel trials, and retrospective studies. We excluded case reports and studies conducted on fewer than 20 patients.

In addition, we retrospectively evaluated 2 years' follow-up of TBZ treatment on motor and cognitive performances and functional abilities in $28 \mathrm{HD}$ patients, compared with 10 patients treated with other neuroleptics (clotiapine). ${ }^{12}$

The clinical outcome of 44 genetically confirmed HD patients, seen for the first time at the Center for Huntington's Disease of the Neurological and Psychiatric Sciences Department of Bari Aldo Moro University, Bari, Italy, and assigned to TBZ or clotiapine treatment, was checked after 24-30 months' (mean $25.5 \pm 2.3$ months) observation. Subjects were titrated to the more efficacious and well-tolerated individual dose for both treatments, with a maximum of $200 \mathrm{mg} /$ day for TBZ and $100 \mathrm{mg}$ for clotiapine. All subjects had been assessed according to the motor section of Unified Huntington's Disease Rating Scale
$(\mathrm{UHDRS})^{13}$ and the Total Functional Capacity Scale ${ }^{14}$ at the first access and after 24-30 months of treatment. The statistical analysis included two-way analysis of variance (ANOVA) with clinical scores as variables and time of observation and treatments as factors. In addition, in order to assess the efficacy of TBZ and clotiapine according to severity of motor disability, we evaluated the correlation between the total maximal chorea score in basal condition and the change occurring after treatment, employing Spearman's correlation test.

\section{Results}

Among the reviewed papers, only three fulfilled all the requested criteria, and one reported results from 28 patients affected by chorea, including an undefined number of HD sufferers.

The Huntington Study Group demonstrated the efficacy of TBZ in the first multicenter, prospective, double-blind, placebo-controlled, dose-finding study of TBZ for the treatment of chorea in HD. ${ }^{15}$ Eighty-four ambulatory patients were randomized (in a 2:1 ratio) to receive either placebo or TBZ for 12 weeks. TBZ was increased over 7 weeks up to a maximum of $100 \mathrm{mg} /$ day or until the desired antichoreic effect occurred or intolerable adverse effects supervened. Primary outcome measure was the reduction of 5.0 units from baseline in the chorea score of the UHDRS in TBZ-treated patients, compared with a reduction of 1.5 units on placebo treatment (Table 1). ${ }^{15}$

\begin{tabular}{|c|c|c|c|c|c|}
\hline $\begin{array}{l}\text { Mean TBZ } \\
\text { dosage }\end{array}$ & $\begin{array}{l}\text { Short-term } \\
\text { change of TMC }\end{array}$ & $\begin{array}{l}\text { Long-term } \\
\text { change of TMC }\end{array}$ & $\begin{array}{l}\text { Clinical global } \\
\text { impression } \\
\text { of change }\end{array}$ & Adverse effects & $\begin{array}{l}\text { Serious adverse } \\
\text { accidents or causes } \\
\text { of withdrawal }\end{array}$ \\
\hline $\begin{array}{l}\text { Up to } 150 \mathrm{mg} / \mathrm{die} \\
(76.2 \pm 38.4 \mathrm{mg} \\
\text { range } 25-175)\end{array}$ & & & $\begin{array}{l}32.14 \% \text { marked } \\
\text { improvement } \\
\text { (among the total } \\
\text { chorea patients) }\end{array}$ & $\begin{array}{l}\text { Not defined in } \\
\text { HD patients }\end{array}$ & $\begin{array}{l}\text { Worsening ( } 3) \text {, lack of } \\
\text { benefit ( } 7 \text { patients with } \\
\text { chorea including HD) }\end{array}$ \\
\hline $\begin{array}{l}\text { Up to } 100 \mathrm{mg} / \mathrm{die} \\
\text { (range } 25-100 \text { ) }\end{array}$ & $\begin{array}{l}-5 \pm 0.5(M \pm S E) \\
(P=0.000 \mathrm{I} \\
\text { vs placebo })\end{array}$ & & $\begin{array}{l}40 \% \text { much } \\
\text { improved } \\
(P=0.0007 \\
\text { vs placebo })\end{array}$ & $\begin{array}{l}\text { Sedation (13), } \\
\text { akatisia (4), } \\
\text { parkinsonism, (2), } \\
\text { depression (5) }\end{array}$ & $\begin{array}{l}\text { Suicide (I), intracerebral } \\
\text { hemorrhage consequent to } \\
\text { a fall }(I) \text {, breast cancer (I) }\end{array}$ \\
\hline $\begin{array}{l}57.5 \pm 14.7 \mathrm{mg} \\
\text { (range } 6.25-150 \text { ) }\end{array}$ & $\begin{array}{l}-21 \%(0-20) \\
(P=0.00001 \\
\text { vs baseline })\end{array}$ & $\begin{array}{l}-9 \%(1-22) \\
\text { (n.s. vs baseline) }\end{array}$ & & $\begin{array}{l}\text { Drowsiness (I7), } \\
\text { depression (I I), } \\
\text { disturbances of } \\
\text { gut function (8), } \\
\text { worsening of } \\
\text { parkinsonism (4), } \\
\text { xerostomia (2), } \\
\text { hypotension (I) }\end{array}$ & $\begin{array}{l}\text { Worsening of psychiatric } \\
\text { disturbance (I), disabling } \\
\text { asthenia (I) }\end{array}$ \\
\hline $\begin{array}{l}\text { Up to } 200 \mathrm{mg} / \mathrm{die} \\
\text { (range } 12.5-175 \mathrm{mg} \text { ) }\end{array}$ & $\begin{array}{l}-5.8 \pm 5(M+S D) \\
(P<0.05 \\
\text { vs baseline })\end{array}$ & $\begin{array}{l}-4.6 \pm 5.5(M+S D) \\
(P<0.05 \\
\text { vs baseline })\end{array}$ & & $\begin{array}{l}\text { Sedation (I8), } \\
\text { depressed mood (I7), } \\
\text { anxiety (I3), } \\
\text { insomnia (I0), } \\
\text { fatigue (7), agitation (5), } \\
\text { fall (4), dysphagia (3), } \\
\text { dystonia (3) }\end{array}$ & $\begin{array}{l}\text { Vocal tics, depression, } \\
\text { delusions ( } 3) \text {; methastatic } \\
\text { breast cancer (I); elevated } \\
\text { bilirubine level, akatisia (I); } \\
\text { elevated liver enzyme (I) }\end{array}$ \\
\hline
\end{tabular}

Abbreviations: HD, Huntington's disease; TBZ, tetrabenazine; TMC, Total Maximal Chorea score. 
The same group of study participants was given the opportunity to participate in an open-label extension study. Subjects who completed the 13-week, double-blind protocol were invited to participate in this open-label extension study for up to 80 weeks. ${ }^{16}$ Of the 75 participants, 45 subjects completed 80 additional weeks of treatment with TBZ. Subjects were titrated to the best individual dose or a maximum of $200 \mathrm{mg}$ /day. Chorea were assessed using the Total Maximal Chorea (TMC) score from the Unified Huntington Disease Rating Scale. ${ }^{13}$ At week 80 , chorea had significantly improved
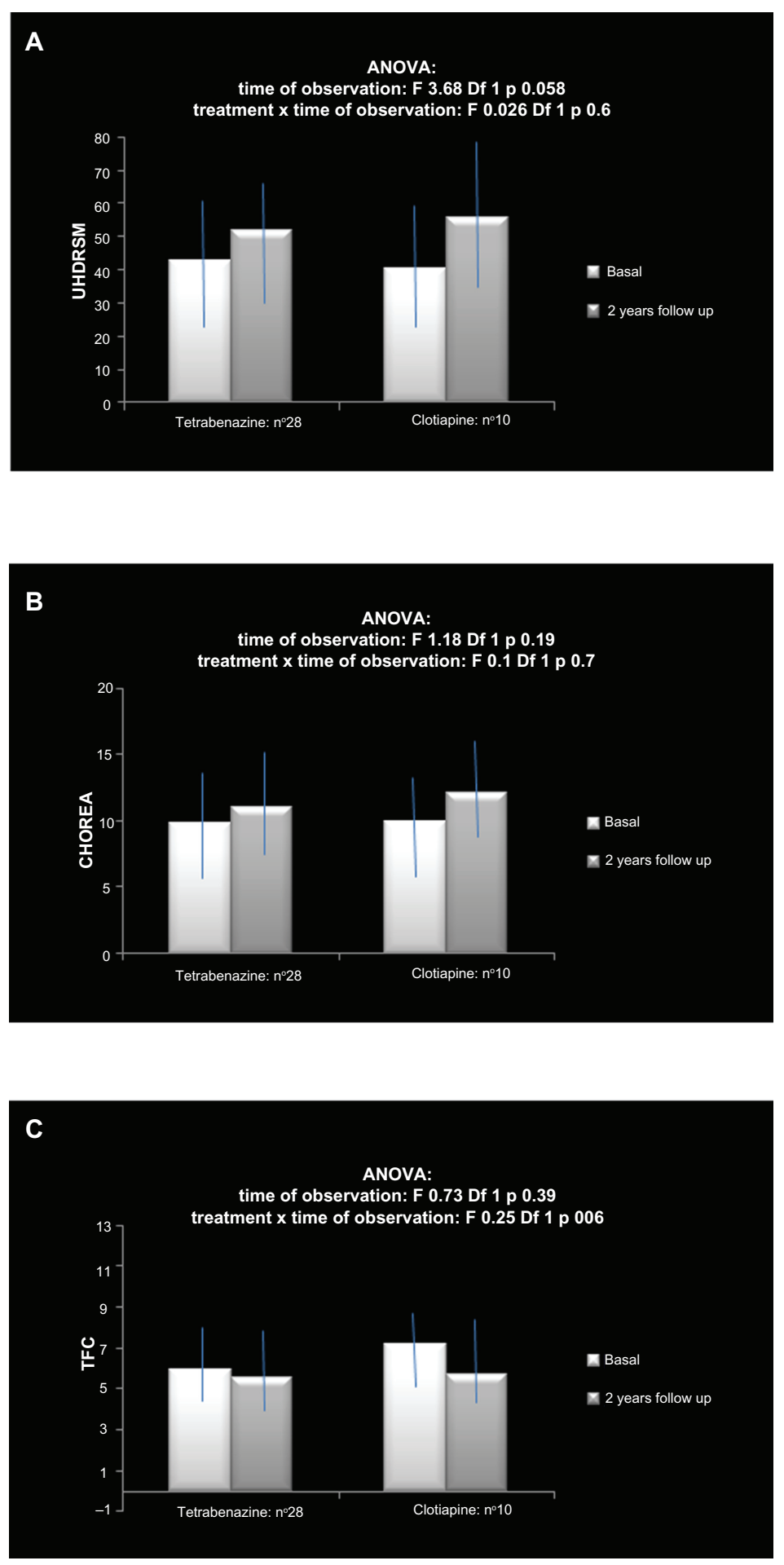

Figure I Mean values and standard deviations of A) the global motor score of the Unified Huntington's Disease Rating Scale (UHDRSM), B) the chorea score, and C) the Total Functional Capacity (TFC) Scale in a cohort of Huntington's disease patients before and after 2 years of treatment. The results of two-way analysis of variance (ANOVA) are reported. 
Table 2 Mean values and standard deviations of the principal clinical features in our HD patients

\begin{tabular}{|c|c|c|c|c|c|c|}
\hline & \multicolumn{3}{|c|}{$\begin{array}{l}\text { Tetrabenazine } \\
\mathbf{N}=\mathbf{2 8}\end{array}$} & \multicolumn{3}{|l|}{$\begin{array}{l}\text { Clotiapine } \\
N=10\end{array}$} \\
\hline & Basal & I year & 2 years & Basal & I year & 2 years \\
\hline TFC & $5.9 \pm 3.9$ & $5.8 \pm 2.3$ & $5.5 \pm 3.9$ & $7.13 \pm 5.4$ & $6.9 \pm 4.5$ & $5.7 \pm 4.3$ \\
\hline UHDRSM & $43.77 \pm 22$ & $44.5 \pm 20$ & $50.21 \pm 27$ & $40.26 \pm 28$ & $44.3 \pm 19.8$ & $55.88 \pm 22.3$ \\
\hline Chorea & $10 \pm 5.96$ & $9.6 \pm 4.66$ & $10.7 \pm 4.29$ & $9.8 \pm 5.4$ & $9.9 \pm 6.3$ & $12.12 \pm 4.2$ \\
\hline
\end{tabular}

Abbreviations: HD, Huntingdon's disease; TFC, Total Functional Capacity Scale; UHDRSM, Motor Section of the Unified Huntington's Disease Rating Scale.

from baseline with a mean reduction in the TMC score of 4.6 (standard deviation 5.5) units. The mean dose at week 80 was $63.4 \mathrm{mg}$ (range 12.5-175 mg). Three participants terminated due to adverse events. The other 26 subjects chose not to continue study extension for various reasons (Table 1).

Fasano et $\mathrm{al}^{17}$ performed a retrospective study to evaluate the long-term efficacy and safety of TBZ in managing chorea. In the study, $68 \mathrm{HD}$ patients were analyzed. Patients were treated with TBZ for a mean period of $34.4 \pm 25.2$ months. At the first follow-up, 9.7 \pm 7.8 months after the prescription of TBZ (mean dose $35.3 \pm 14.7 \mathrm{mg}$ ), mean score of chorea was $8.2 \pm 4.1$ ( $-21 \%$ compared with baseline), whereas at the latest follow-up visit (mean dose $57.5 \pm 14.7 \mathrm{mg}$ ), it was $9.5 \pm 5.0(9 \%)$. During the follow-up, the clinical benefit persisted, but the magnitude was reduced despite a progressive increase of the doses (up to $60 \%$ ). Five patients (7\%) did not gain any improvement, and TBZ was discontinued. There were two withdrawals because of side effects; 34 patients reported at least one side effect (Table 1).

The authors reported that TBZ was well tolerated and produced long-term improvement of motor symptoms in HD patients, although a slight reduction of benefit occurred during the course of treatment. ${ }^{17}$

Paleacu et a ${ }^{18}$ studied a total of 118 patients with hyperkinetic movement disorders, including a group of 28 subjects with chorea, with an unpredictable number of HD sufferers. Patients were assessed in the follow-up visit or by direct and telephone interview using the Clinical Global Impression of Change (CGIC), and the overall efficacy of treatment was shown via a composite score made up from the patient's and the caregiver's score. ${ }^{18}$ Significant improvement of hyperkinesias was seen in $61 \%$ of patients, with a subgroup of subjects with chorea (nine, including an undefined number of HD patients) and facial dyskinesias responding most favorably (Table 1). ${ }^{18}$

\section{Our experience}

Among 44 patients, 32 had been assigned to TBZ and 12 to clotiapine treatment. Four patients in the TBZ group and two in the clotiapine group were lost to the 2-year follow-up (two patients were hospitalized, two changed address, and two further patients discontinued TBZ after 2 months' therapy because of the sedation side effect). The remainder of the patients took the assigned treatment during the observation period, though in 10 patients in the TBZ group and five in the clotiapine group the minimum efficacious dosage was further reduced because of the occurrence of side effects (sedation, depression, and confusion in both groups), which were relatively resolved at the 2-year follow-up (two patients in the TBZ group and one in the clotiapine group reported sedation; two patients on TBZ reported fatigue). As a consequence, the TBZ dose was, on average, $75 \pm 15 \mathrm{mg}$ and the clotiapine dose was $30 \pm 5.5 \mathrm{mg}$. The motor performances worsend in a nonsignificant way in both groups, without significant differences between the two treatments (Table 1; Figure 1A). In particular, in the TBZ group, the progression of chorea seemed slightly reduced compared with the clotiapine group (Table 1; Figure 1B). In fact, the mean change of chorea score over time was $+0.85 \pm 2.5$ in the TBZ group and $+2.3 \pm 4.5$ in the clotiapine group ( $t$-test: nonsignificant). The functional capacities remained stable at follow-up in the TBZ group, with a slight deterioration in the clotiapine group (Table 1; Figure 1C).

The change of chorea score correlated in a negative way with the basal values in the TBZ group (Spearman's correlation test in the TBZ group: $0.521, P=0.002$; in the clotiapine group: 0.564, nonsignificant), suggesting more effect in patients with severe hyperkinesias.

\section{Conclusion}

Few studies have evaluated the efficacy of TBZ in large samples of HD patients, though it is the only approved drug for HD. In general, the symptomatic treatment of HD has not been evaluated in large cohorts of patients, and there are many aspects of the disease, such as other abnormal involuntary movements, cognition, affective disorders, and behavioral disturbances, for which the best therapeutic strategies are not determined. ${ }^{19,20}$ Only one study ${ }^{15}$ reported results of a short-term, double-blind, placebo-randomized design, and only one prospective ${ }^{16}$ and one retrospective ${ }^{17}$ study on the long-term effect of TBZ are available. A study 
by Paleacu et al ${ }^{18}$ did not explain the exact number of HD patients studied. In addition, the comparison between TBZ and other classical neuroleptics has not been extensively studied in any study. Brusa et $\mathrm{al}^{21}$ compared the effects of TBZ with those obtained by aripiprazole in six HD patients, finding a slightly prevalent effect of TBZ on chorea but a greater tolerability of aripiprazolo concerning sedation and depression. The overall evaluation of the results obtained from the few TBZ studies on HD seems to partly support its efficacy on choreatic movements. The potential adverse effects of TBZ need a careful evaluation and dosage adjustment. ${ }^{22}$ In fact, TBZ causes several adverse events, which in many cases has determined its reduction or even withdrawal. The dosage seems to vary conspicuously across studies and in the same patient group, in an attempt to balance efficacy and tolerability. In addition, the efficacy of TBZ is contrasted with the natural progression of the disease and the loss of efficacy. ${ }^{17}$ Our observation confirms that in long-term studies the balance between efficacy and tolerability reduces the potential effect on motor symptoms of both TBZ and the considered atypical neuroleptic drug. In fact, compared with cases reported in previous studies, in our patients, TBZ exhibited a global reduction of efficacy concurring with a minor representation of adverse effects at the 2-year follow-up. Moreover, the worsening of chorea was not significant in both groups and appeared to be further reduced in TBZ-treated patients. The stability of functional capacities across time suggests that the medium-low drug dosages may partly reduce the progression of chorea without compromising other abilities or the occurrence of strong depression, sedation, or confusion. Animal studies have pointed to an important role of the dopaminergic pathway in HD and have suggested that the dopamine signaling pathway constitutes a potential therapeutic target for HD treatment. ${ }^{23,24}$ Recently, long-term feeding with TBZ (combined with levodopa) alleviated the motor deficits and reduced the striatal neuronal loss in the mouse model of HD, thus suggesting a neuroprotective effect. ${ }^{25}$ However, our retrospective observation does not exclude a lack of effect of both treatments on illness progression, for the absence of a placebo group, and may contribute to confirming the hypothesis suggested by Fasano et al with regard to a long-term loss of efficacy. ${ }^{17}$ Nevertheless, we observed a major effect in patients presenting with more severe chorea, indicating an efficacy of TBZ in the progression of motor deterioration. The hypothesis that TBZ may act as a neuroprotective rather than a symptomatic drug should be tested in more prolonged study designs. ${ }^{25}$ The overall impression being derived from the available data and our personal experience is that the problems linked with the symptomatic treatments need further study in HD, especially when the long-term outcome has to be considered, also taking into consideration comparison with the efficacy and tolerability of typical and atypical neuroleptics frequently used in HD patients. Despite the global effect of TBZ seeming positive in HD, more attention on evaluating symptomatic treatments for cognitive and psychiatric deterioration as well as motor deterioration would contribute to alleviating this devastating disorder until a protective treatment against progressive neurodegeneration becomes available.

\section{Disclosure}

The authors report no conflicts of interest in this work.

\section{References}

1. Bates G, Harper P, Jones L. Huntington's Disease, 3rd ed. Oxford: Oxford University Press; 2002.

2. The Huntington's Disease Collaborative Research Group. A novel gene containing a trinucleotide repeat that is expanded and unstable on Huntington's disease chromosomes. Cell. 1993;72(6):971-983.

3. Leonard DP, Kidson MA, Brown JG, et al. A double blind trial of lithium carbonate and haloperidol in Huntington's chorea. Aust $N Z J$ Psychiatry. 1975;9(2):115-118.

4. Barr AN, Fischer JH, Koller WC, et al. Serum haloperidol concentration and choreiform movements in Huntington's disease. Neurology. 1988; 38(1):84-88.

5. Frank S. Tetrabenazine: the first approved drug for the treatment of chorea in US patients with Huntington disease. Neuropsychiatr Dis Treat. 2010;6:657-665.

6. Scherman D, Jaudon P, Henry JP. Characterization of the monoamine carrier of chromaffin granule membrane by binding of [2-3H]dihydrotetrabenazine. Proc Natl Acad Sci U S A. 1983;80:584-588.

7. Mehvar R, Jamali F. Concentration-effect relationships of tetrabenazine and dihydrotetrabenazine in the rat. J Pharm Sci. 1987;76: 461-465.

8. Thibaut F, Faucheux BA, Marquez J, et al. Regional distribution of monoamine vesicular uptake sites in the mesencephalon of control subjects and patients with Parkinson's disease: a postmortem study using tritated tetrabenazine. Brain Res. 1995;692:233-243.

9. Login IS, Cronin MJ, MacLeod RM. Tetrabenazine has properties of a dopamine receptor antagonist. Ann Neurol. 1982;12:257-262.

10. Reches A, Burke RE, Kuhn CM, et al. Tetrabenazine, an aminedepleting drug, also blocks dopamine receptors in rat brain. J Pharmacol Exp Ther. 1983;225:515-521.

11. Burke RE, Reches A, Traub MM, et al. Tetrabenazine induces acute dystonic reactions. Ann Neurol. 1985;17:200-202.

12. Gauch R, Lehner H. The metabolism of 2-chloro-11-(4-methyl-1piperazinyl) dibenzo-(b,f)(1,4)-thiazepine (clotiapine). 3. The metabolism and excretion in the human. Farmaco Prat. 1969;24(2):100-109.

13. Huntington Study Group. Unified Huntington's disease rating scale: reliability and consistency. Mov Disord. 1996;11:136-142.

14. Shoulson I. Huntington's disease: functional capacities in patients treated with neuroleptic and antidepressant drugs. Neurology. 1981;31: 1333-1335.

15. Huntington Study Group. Tetrabenazine as antichorea therapy in Huntington disease: a randomized controlled trial. Neurology. 2006; 66(3):366-372. 
16. Frank S. Tetrabenazine as anti-chorea therapy in Huntington disease: an open-label continuation study. Huntington Study Group/TETRA-HD Investigators. BMC Neurol. 2009;9:62.

17. Fasano A, Cadeddu F, Guidubaldi A, et al. The long-term effect of tetrabenazine in the management of Huntington disease. Clin Neuropharmacol. 2008;31(6):313-318.

18. Paleacu D, Giladi N, Moore O, et al. Tetrabenazine treatment in movement disorders. Clin Neuropharmacol. 2004;27:230-233.

19. Ross CA, Tabrizi SJ. Huntington's disease: from molecular pathogenesis to clinical treatment. Lancet Neurol. 2011;10(1):83-98.

20. Poon LH, Kang GA, Lee AJ. Role of tetrabenazine for Huntington's disease-associated chorea. Ann Pharmacother. 2010;44(6):1080-1089.

21. Brusa L, Orlacchio A, Moschella V, et al. Treatment of the symptoms of Huntington's disease: preliminary results comparing aripiprazole and tetrabenazine. Mov Disord. 2009;24(1):126-129.
22. Guay DR. Tetrabenazine, a monoamine-depleting drug used in the treatment of hyperkinetic movement disorders. Am J Geriatr Pharmacother. 2010;8(4):331-373.

23. Tang TS, Chen X, Liu J, Bezprozvanny I. Dopaminergic signaling and striatal neurodegeneration in Huntington's disease. JNeurosci. 2007;27: 7899-7910.

24. Paoletti P, Vila I, Rife M, et al. Dopaminergic and glutamatergic signaling crosstalk in Huntington's disease neurodegeneration: the role of p25/ cyclin-dependent kinase 5. J Neurosci. 2008;28:10090-10101.

25. Wang H, Chen X, Li Y, et al. Tetrabenazine is neuroprotective in Huntington's disease mice. Mol Neurodegener. 2010;5:18-33.

\section{Publish your work in this journal}

Therapeutics and Clinical Risk Management is an international, peerreviewed journal of clinical therapeutics and risk management, focusing on concise rapid reporting of clinical studies in all therapeutic areas, outcomes, safety, and programs for the effective, safe, and sustained use of medicines. This journal is indexed on PubMed Central, CAS,

\section{Dovepress}

EMBase, Scopus and the Elsevier Bibliographic databases. The manuscript management system is completely online and includes a very quick and fair peer-review system, which is all easy to use. Visit http://www.dovepress.com/testimonials.php to read real quotes from published authors.

Submit your manuscript here: http://www.dovepress.com/therapeutics-and-clinical-risk-management-journal 